\title{
Decision Support System Development at the Upper Midwest Environmental Sciences Center
}

A Decision Support System (DSS) can be defined in many ways. The working definition used by the U.S. Geological Survey Upper Midwest Environmental Sciences Center (UMESC) is, "A spatially based computer application or data that assists a researcher or manager in making decisions." This is quite a broad definition - and it needs to be, because the possibilities for types of DSSs are limited only by the user group and the developer's imagination. There is no one DSS; the types of DSSs are as diverse as the problems they help solve. This diversity requires that DSSs be built in a variety of ways, using the most appropriate methods and tools for the individual application. The skills of potential DSS users vary widely as well, further necessitating multiple approaches to DSS development. Some small, highly trained user groups may want a powerful modeling tool with extensive functionality at the expense of ease of use. Other user groups less familiar with geographic information system (GIS) and spatial data may want an easy-to-use application for a nontechnical audience. UMESC has been developing DSSs for almost 20 years. Our DSS developers offer our partners a wide variety of technical skills and development options, ranging from the most simple Web page or small application to complex modeling application development. The following sections describe some of the DSSs we have recently developed and one project that is currently under development.

\section{Curve Fit: A Pixel Level Raster Regression Tool}

Curve Fit has the ability to capture cause and effect relationships as a spatially explicit mathematical model, thus making Curve Fit an invaluable tool for landscape ecology and modeling. Curve Fit performs regression analysis at the pixel level, using georeferenced imagery as input data. As with all regression tools, Curve Fit has both predictive and explanatory applications. Curve Fit's predictive aspects are demonstrated by its ability to fit a mathematical model to observed events (for example, the relationship between the discharge rate of a river dam to the resulting water depth downstream). Curve Fit enables the user to move from a set of discrete observations to a single continuous solution, with the ability to calculate all intermediary outcomes (for example, a user specifies a discharge rate and calculates a map showing the resulting water depth at that rate). Curve Fit's explanatory applications are illustrated through its ability to generate maps that help visualize or quantify the rate or scale of landscape change (for example, generating maps that show the rate of habitat fragmentation over time). Curve Fit operates as an extension to the GIS application ArcMap. Utilizing both linear and nonlinear regression models, Curve Fit outputs georeferenced images that represent parameter estimate, model error, and multimodel inference. http://www.umesc.usgs.gov/management/dss/curve fit.html
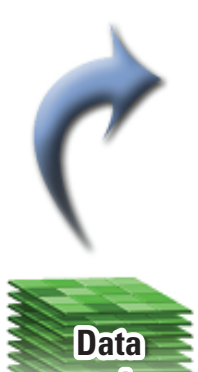

series

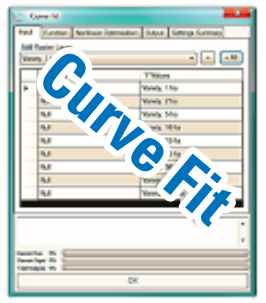

Parameter estimates (coefficients)
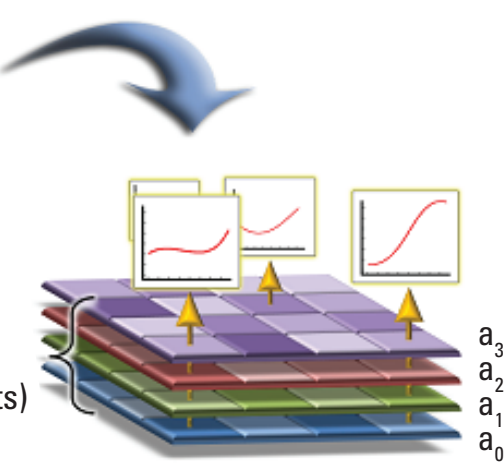

Third degree polynomial $a_{3} x^{3}+a_{2} x^{2}+a_{1} x+a_{0}$

\section{Wave Model}

The ability to quantify the physical impact of wind and, subsequently, wave energy has become an important tool for analyzing aquatic habitats because areas with large waves are susceptible to erosion, increased turbidity, and subsequently decreased aquatic vegetation growth. The U.S. Army Corps of Engineers (USACE) encouraged UMESC to develop a decision support model that would allow them to generate several different physical wave characteristics. The application of this model gives researchers and resource managers the capability to better design habitat rehabilitation structures and

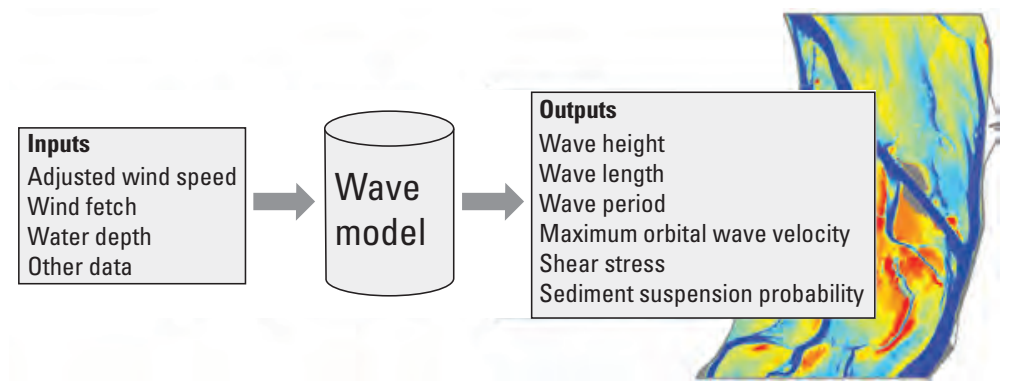

predict their effects. Significant wave height, wave length, spectral peak wave period, shear stress, and maximum orbital wave velocity can all be calculated by using this model according to equations taken from the USACE Shore Protection Manual and the USACE Coastal Engineering Manual. This model was developed as a toolbox within ArcGIS 10.1 and uses wind fetch, wind direction, wind speed, and bathymetric data as inputs to calculate the wave outputs. The model also allows the user to calculate the probability that aquatic areas will have maximum orbital wave velocities sufficient to suspend sediments, based on the wind speed and direction data used and a user-defined maximum orbital wave velocity threshold. This model was funded by and prepared for the USACE Upper Mississippi River Restoration-Environmental Management Program.

http://www.umesc.usgs.gov/management/dss/wind_fetch_wave_ models_2012update.html 


\section{A Tool for Prioritizing Management Units at Morris Wetland Management District}

Resource conservation agencies that manage numerous dispersed habitat conservation units over a large spatial area often struggle with how to prioritize the management of these units on the basis of fiscal and staffing limitations. In an effort to provide a scientifically based, landscape-scale method for evaluating waterfowl production areas (WPAs) at the U.S. Fish and Wildlife Service's Morris Wetland Management District, UMESC developed spatially explicit models to assess these units on the basis of several agency-defined objectives. These models operate via a system of weighted overlays. In addition, tools were developed to make these models dynamic to allow for flexibility in response to potential shifts in agency philosophies and objectives. Because the input variables and weighting included in the models were developed by those also responsible for managing the conservation units, the output from the models were well received and are currently being used by the district for future planning. For example, the accompanying map image shows overall prioritization model results; WPAs with the top 10 scores for this model are labeled. This tool was funded by the U.S. Fish and Wildlife Service.

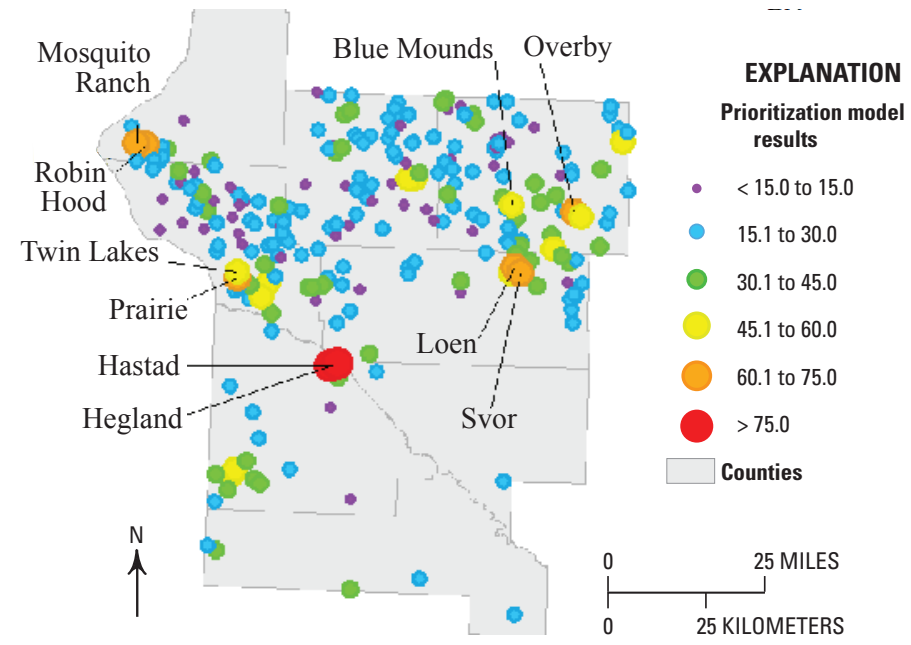

http://www.umesc.usgs.gov/management/dss/morris_wmd.html

\section{Inundation and Connectivity Tool}

The Inundation and Connectivity Tool allows researchers to investigate the timing, degree, and duration of hydrological conditions on the Upper Mississippi River (UMR) and helps give them a better understanding of contributing factors that influence water quality, vegetation growth, and animal habitat on the UMR. UMESC often leverages the capabilities of one DSS project to bolster the development of new DSS applications. Such is the case of the Inundation and Connectivity Tool. This application uses Curve Fit regression models and a database of UMR water conditions to model spatial products describing bathymetry, flow velocity, and systemic connectivity over a specified date range. Using a simple query interface, an investigator can produce maps describing the extent, intensity, and duration of flooding events. Other examples of Inundation and Connectivity Tool applicability include the creation of maps showing the number of days that water exceeded a specified flow velocity, summary statistics of water depth over a specified timespan, or the number of days a particular backwater area was systemically connected to the UMR. The Inundation and Connectivity Tool is an extremely flexible application in that it allows for incorporation of new models and hydrological data so that it can be easily adapted to different river systems.

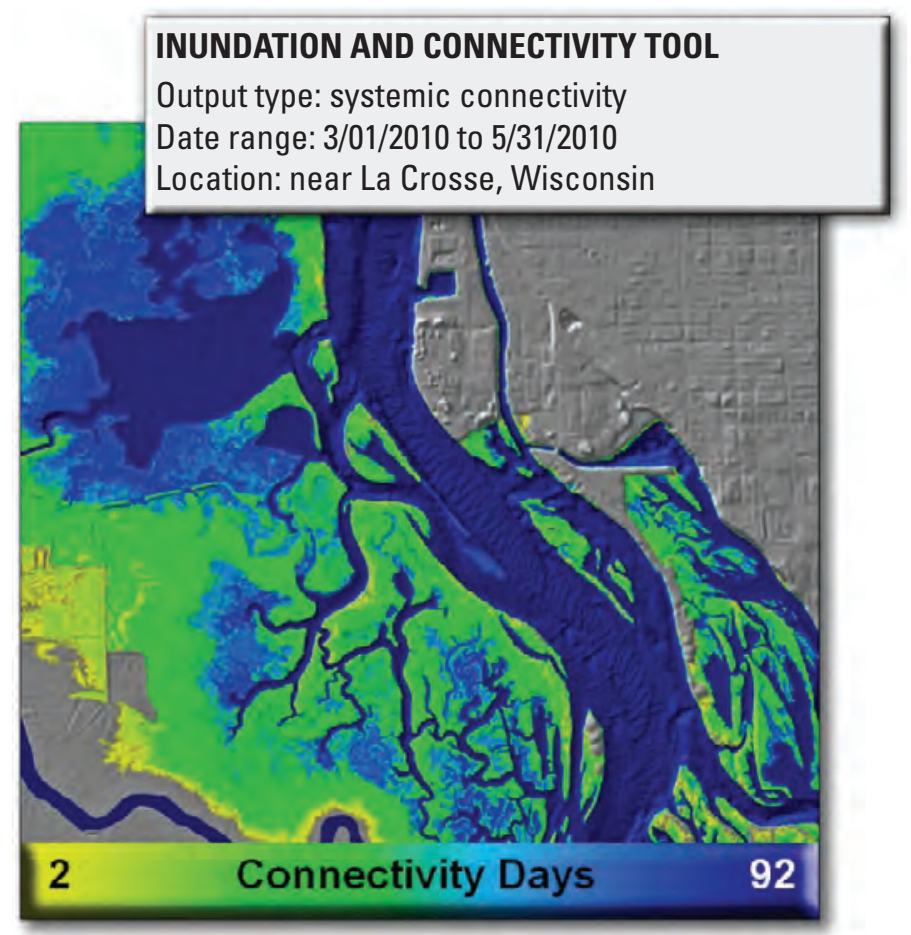

\section{For more information, contact}

USGS Upper Midwest Environmental Sciences Center

2630 Fanta Reed Road

La Crosse, WI 54603

http://www.umesc.usgs.gov/dss.html

$\begin{array}{lll}\text { Timothy J. Fox } & \text { John C. Nelson } & \text { Jason J. Rohweder } \\ 608.781 .6342 & 608.781 .6370 & 608.781 .6228 \\ \text { tfox@usgs.gov } & \text { jcnelson@usgs.gov } & \text { jrohweder@usgs.gov }\end{array}$

ISSN 2327-6932 (online) 